\title{
Effects of Public Hospital Reform on Inpatient Expenditures in Rural China
}

\author{
Yuting Zhang ${ }^{\mathrm{a}}$, Qianheng Ma ${ }^{\mathrm{b}}$, Yingchun Chen ${ }^{\mathrm{c}, \mathrm{d}}$, Hongxia Gao ${ }^{\mathrm{c}, \mathrm{d}}$
}

a Department of Health Policy and Management, Graduate School of Public Health, University of Pittsburgh, 130 De Soto St, Pittsburgh, PA 15261, USA

b Department of Biostatistics, Graduate School of Public Health, University of Pittsburgh, PA 15261,USA

c School of Medicine and Health Management, Tongji Medical College, Huazhong University of Science \& Technology, Wuhan, 430030, China.

d Research Center for Rural Health Service, Key Research Institute of Humanities \& Social Sciences of Hubei Province, Wuhan, 430030, China.

Running title: (max 50 characters): Effects of Public Hospital Reform in Rural China

Keywords (2-6): public hospital reform, China, healthcare expenditures

\section{Manuscript word: $3185 ; 3$ tables and 2 figures}

The institution at which the research was conducted: Data collection was conducted at the Huazhong University of Science \& Technology; and analyses and manuscript preparation were conducted at the University of Pittsburgh.

Corresponding author: Hongxia Gao, School of Medicine and Health Management, Tongji Medical College, Huazhong University of Science \& Technology, 13 Hongkong Road, Wuhan, Hubei, 430030, China; Phone: 86-27-83691017; Fax: 86-27-83692996; Email: gaohongxia@hust.edu.cn

This is the author manuscript accepted for publication and has undergone full peer review but has not been through the copyediting, typesetting, pagination and proofreading process, which may lead to differences between this version and the Version of Record. Please cite this article as doi: 10.1002/hec.3320 
Funding sources: We acknowledge funding from Project 2013WT011 supported by Chinese Fundamental Research Funds for the Central Universities.

\section{Conflict of interest disclosures: none}

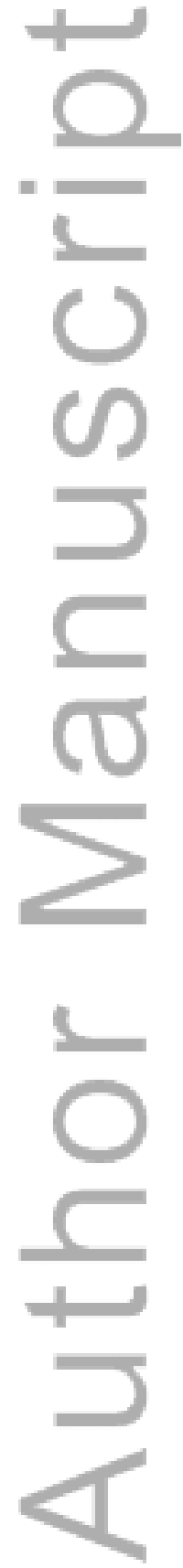

This article is protected by copyright. All rights reserved. 
Effects of Public Hospital Reform on Inpatient Expenditures in Rural China

Running title: (max 50 characters): Effects of Public Hospital Reform in Rural China Keywords (2-6): public hospital reform, China, healthcare expenditures

Manuscript word: $3185 ; 3$ tables and 2 figures

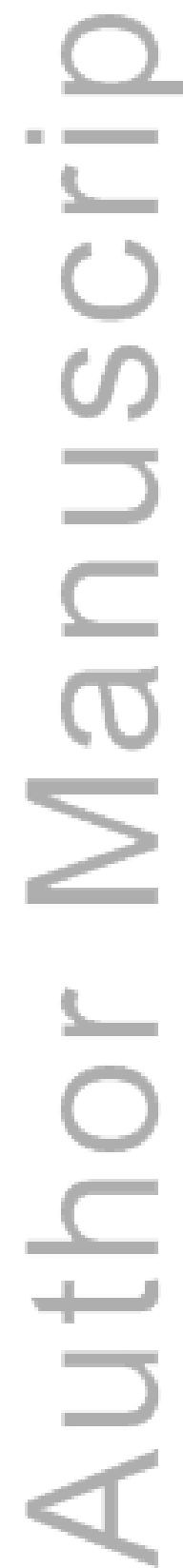




\section{Abstracts (WC: 200; 200 words limit)}

Public hospital reform is one priority area in the healthcare system reform that China launched in 2009. The Chinese government invested over $\$ 10$ billion for pilot projects in public hospital reform in rural China. However, little evidence exists on their effects. Using a quasi-natural experiment design, we evaluated the effects of a public hospital pilot project in Hubei province on inpatient spending. We obtained inpatient claims data from 1/1/2011 through 6/30/2013 for enrollees in the New Cooperative Medical Scheme in two counties: Danjiangkou, one of the pilot counties selected for reform in September 2012; and Laohekou, a similar, adjacent county serving as the control group. Using a difference-in-differences approach with propensity-score-weighting, we found that total inpatient spending increased CNY1160 (95\% CI 1155-1166), out-of-pocket spending increased CNY385 (95\% CI 382-389), length of stay increased 0.51 days (95\% CI 0.50-0.52), but inpatient medication spending decreased CNY147 (95\% CI 145-150), post policy in Danjiangkou, relative to the control group. The overall reimbursement rate increased by 5.7 percentage points. One of the goals of the recent public hospital reform is to make inpatient services affordable to patients. We found that although patients spent less on inpatient medications, total out-of-pocket spending increased considerably after reform. 


\section{Introduction}

China's most recent healthcare system reform was launched in 2009. One of the reform's five priority areas is to conduct pilot projects for public hospital reform. Over $90 \%$ of inpatient and emergency services in China are delivered in public hospitals (Barber et al., 2014). In addition, for simple outpatient health problems, Chinese patients commonly seek care in large hospitals. Thus, public hospital reform plays a critical role in improving the quality of care, reducing overuse of inpatient pharmaceuticals, controlling healthcare expenditures, and making inpatient services affordable to patients, especially in rural areas.

The registered rural population accounts for $60 \%$ of the Chinese total population and they obtain their health insurance from the New Cooperative Medical Scheme (NCMS) (Wagstaff et al., 2009, Jing et al., 2013). In 2012, in Hubei province, the average official reimbursement rate for inpatient expenditures was $78 \%$ for services that were covered by NCMS for rural residents who obtained their medical care from their local hospitals (New Cooperative Medical Scheme Council of Hubei Province, 2012). But the actual reimbursement rate is often much lower than the official number, because many services provided in the hospital are not covered by NCMS. In addition, the reimbursement rate varies by county, depending on each county's economic development and hospitalization rates.

The Chinese government has decided to put an emphasis on comprehensive reform of county-level public hospitals. As a result, many pilot counties are going through various forms of public hospital reforms. The first phase of county-level public hospital reform started in June 2012 (The State Council of the People's Republic of China, 2012) for a selected group of 311 pilot counties. The second phase 
started in 2014 for 700 pilot counties. The government has planned to complete the pilot projects and expand the reform throughout the entire country in 2015 . The central government has invested about 63 billion RMB (approximately 10 billion USD) to support county hospitals and township and village medical and health institutions (World Health Organization). Local governments have also increased capital inputs for public hospital reform.

The county-level public hospital reform consists of several components: first, the government adjusts medication prices and removes the mark-up on medications that are on the National Essential Medicine list; the policy is known as zero-markup prescription drug policy. Before the reform, a mark-up of at least $15 \%$ was allowed on all drugs that were dispensed in the hospitals and it has caused severe overprescribing of medications (Li et al., 2013). After the reform, hospitals technically can only charge a mark-up rate on the drugs that are not on the National Essential Medicine list. As of 2011, drug sales were the largest revenue source in public hospitals (Yu et al., 2010, Zhao et al., 2013). Second, to make up the reduction in revenue due to the zero-markup drug policy, the hospitals are allowed to charge higher prices for medical services, especially for services that require high-level professional skills, such as physician diagnostic and surgical charges. However, the prices for these non-drug services are set by the provincial government and hospitals cannot charge extra on the set prices.

In response to the central government's call for county public hospital reforms, provinces set up their own policies and selected pilot counties. Hubei province started the county public hospital reform on September 10, 2012 and initially selected 20 pilot counties (The Government of Hubei Province, 2012). The main reform includes 
the following areas: to remove medication mark-up, to raise charges for medical services that require professional skills (physician services and surgical fees), and to lower charges for advanced medical diagnostic devices. For example, in Danjiangkou, one of the pilot counties, outpatient clinical fees increased by CNY 11 per visit (from CNY 2 to CNY 13), and inpatient service fees per inpatient day increased by CNY 33 (from CNY 6 to CNY 39) (The Government of Hubei Province, 2012). Unlike private hospitals, public hospitals in China cannot set their own prices for services provided in the hospitals and all service prices are set by the provincial government. In Hubei public hospitals, the Hubei Price Bureau sets new prices that are used in pilot counties, and old prices are used for other non-pilot counties. The county level government or public hospitals cannot set their own prices.

A recent study summarized the progress in the implementation of 16 pilot cities for public hospital reforms (Yip et al., 2012). Two of the 16 pilot cities chose to primarily rely on market competition, while the rest chose to focus on reforming governance. Many city governments accompanied changes in financing, payment and human resources. Cities began to implement reform around mid-December in 2010 and counties started pilot programs in 2012. However, no evidence-based evaluation of public hospital reforms has been reported, especially using real-world hospital data in rural China.

We obtained enrollment information and medical claims data for all NCMS enrollees in two rural counties in Hubei province: Danjiangkou county is one of the pilot counties chosen for the first round of the county public hospital reform that started in September 2012, and Laohekou county, as comparison group, is the adjacent county with similar economic development and population size but did not 
go through similar changes during the study period. We evaluated how the county public hospital reform affects the total inpatient spending, out-of-pocket spending, as well as spending by type of services, 21 months before the policy and 9 months after the policy change.

\section{Methods}

\subsection{Study Design and Data Sources}

We obtained 2011-2013 enrollment information and insurance claims for all NCMS enrollees in two adjacent counties, Danjiangkou (DJK) and Laohekou (LHK), in the northwest region of Hubei province. The two counties are similar in their economic development, geographic location, and population size. As of 2011, DJK had a population of about 440,000, of which 271,492 (61.7\%) were rural residents and therefore gained their health insurance from NCMS; LHK had a population of about 530,000 , of which 316,396 (59.7\%) were rural residents. [NCMS only have claims for those rural residents in the county, but not for those residents who live in the county and have urban ID registration. Urban residents obtain their health insurance through urban resident or employee medical insurance.] In 2011, The Gross Domestic Product (GDP) per capita was CNY 24,707 $(\$ 3,985)$ in DJK, and CNY 20,942 $(\$ 3,378)$ in

\section{LHK.}

DJK was one of the pilot counties selected in Hubei province to implement the county public hospital reform on September 10 2012; but LHK was not one of the pilot counties selected for the reform during the study period. Thus, DJK is our intervention county, and LHK is our control county. The pre-policy period is between January 12011 and September 9, 2012; and the post-policy period is between September 10, 2012 and June 30, 2013. We evaluate the changes in medical spending 
before and after the reform in DJK, relative to the change in LHK during the same period.

Our data files include a personal information file, an inpatient claims file, and an itemized spending file. First, the personal information file includes demographic and socioeconomic variables, such as enrollee ID, sex, age, whether one is the head of a household, and whether one lives in a household that is under poverty line. Second, inpatient file includes diagnoses, admission and discharge dates, hospital name and spending (total spending, reimbursement amount, and patient payment amount). We selected the inpatient claims of public hospitals in both counties. Third, the itemized spending file indicates spending categories including inpatient medications, physician services, inpatient facility fees, diagnostic testing (e.g., blood test and gynecological examination), and therapeutic services (e.g., intravenous infusion, electrotherapy, acupuncture, and nursing services).

\subsection{Outcomes}

We calculated total inpatient spending, as well as spending broken-down by type of services including inpatient medications, physician services, diagnostic testing, therapeutic services, and others. We also broke down into patient out-of-pocket spending and government reimbursement payment, and calculated the overall reimbursement ratio as total government payment divided by total inpatient spending. This rate is not the same as the reimbursement rate officially reported by NCMS for inpatient care, because many services provided in the hospitals are not covered by NCMS and therefore patients have to pay $100 \%$. Finally, we calculated length of inpatient stay. All these outcomes were calculated for per individual per inpatient visit. In addition, to present the unadjusted monthly trend, we also calculated the 
aggregated average spending by calendar month among those who were admitted to the hospitals in the month.

\subsection{Independent variables and covariates}

The three key independent variables are policy intervention indicator (1=Danjiangkou County; 0=Laohekou County), post-policy indicator ( 1 for the postpolicy period between September 10, 2012 and June 30, 2013; 0 for between January 1, 2011 and September 9, 2012), and their interaction term.

Key patient characteristics include age (categorized into 4 groups, $\leq 17$ years, 18 to 34,35 to 64 , and $\geq 65)$, sex $(1=$ male; $0=$ female), poverty level ( $1=$ from a poor family, defined as the annual income being below the national poverty line of China, about CNY 2300 (\$371) for one person in 2012; 0=not from a poor family), and whether the patient was the head of the household ( $1=$ yes; $0=$ no).

In addition, we controlled for year and season fixed effects to adjust for unobserved underlying factors that change over time or by quarter.

\subsection{Statistical Analysis}

We plotted the monthly trend of the aggregated raw spending by county to compare the unadjusted outcomes between the intervention and control groups. Our key identification strategy is a difference-in-differences approach to estimate the preand post- changes in all outcomes in the intervention county, relative to the changes in the control county. To further balance the intervention and control groups, we used a propensity score weighting mechanism. This approach consists of two steps. In the first step, we conducted logistic regressions to estimate the probability of being in the intervention group after adjusting for all the covariates mentioned above. We then calculated the inverse probability of treatment weights, effectively assigning higher 
weights to individuals in the control group that had characteristics similar to those of individuals in the intervention group (Leslie and Ghomrawi, 2008, Zhang et al., 2009). In the second step, we used generalized linear regressions with propensity score weights.

In addition, some of our outcomes do not follow normal distributions. For each outcome, we used modified Park tests to estimate family distribution and box-cox tests to estimate the link function used in the generalized linear regression models (results from modified Park tests and box-cox tests are in the Appendix). In particular, based on the test results, we used log link and poisson distribution for spending for medications and other services, log link and gamma family distribution for all the other spending variables, identity link and Gaussian family distribution for reimbursement rates, and log link and inverse Gaussian family distribution for length of stay.

We estimated predicted values for pre- and post- policy outcomes separately for the intervention and control groups and used bootstrapping techniques with 1000 replications to estimate the standard errors for difference-in-differences estimates. The propensity score weighting and generalized linear regressions were conducted in each bootstrapping iteration. In all the regression models, we adjusted for individual level characteristics mentioned above, as well as the year and season fixed effects. In addition, for all outcomes except for length of stay, we also controlled for length of stay to adjust the severity of illness captured by length of stay. The Ethics Committee of Tongji Medical College, Huazhong University of Science and Technology approved the study protocol.

\section{Results}




\subsection{Study sample characteristics}

Table I shows summary characteristics of rural patients who had any inpatient stay in 2011, with Part A for unweighted raw data and Part B for adjusted data with propensity score weights. The mean unadjusted ages of patients were 43 in DJK and 42 in LHK. The average raw inpatient spending per inpatient stay was CNY 4039 in DJK in 2011, of which spending for inpatient medications was CNY 1482, accounting for $36.7 \%$ of total inpatient spending. Spending for diagnostic testing was CNY 809, accounting for $20 \%$ of the total inpatient spending, followed by physician services and therapeutic services, each accounting for $18 \%$ of total inpatient spending. In LHK, total inpatient spending was slightly lower than that in DJK, but spending for diagnostic testing and spending for therapeutic services were higher. The average reimbursement rates in 2011 were $43.6 \%$ in DJK and 37.8\% in LHK. The average unadjusted length of an inpatient stay was around 11 days in both counties.

After propensity score weighting, all characteristics except for the percentage from the poor family are comparable between two groups.

[Table I is about here]

\subsection{Monthly inpatient spending between January 1, 2011 and June 30, 2013}

Figure 1 presents monthly unadjusted inpatient spending, separately for the government reimbursement amount and patient out-of-pocket spending. Total inpatient spending and the government reimbursement amount increased considerably post policy in the intervention county, but they remained similar in the comparison county.

[Figure 1 is about here]

Figure 2 shows monthly unadjusted inpatient spending, categorized by type of 
services. Physician services spending increased substantially during the post-policy period in the intervention county, but did not change during the same period in the control county. Both counties had baseline increasing trends in inpatient drug spending, but after policy, the increasing trend reversed in the intervention county. The spending for diagnostic testing was considerably higher in the control county, relative to that in the intervention county. Spending for therapeutic services increased in the intervention county but declined in the control county.

[Figure 2 is about here]

\subsection{Policy effects on inpatient spending, out-of-pocket spending, and length of stay}

Table II Part A reports the policy effects on total inpatient spending, out-of-pocket spending, reimbursement rate, and length of stay from the difference-in-differences approach. The interaction term between the intervention and post-policy indicators represents the policy effects. Table II Part B reports the estimates and standard errors of the policy effects from the bootstrapping results. Relative to the control county (LHK), individual inpatient spending in the intervention county (DJK) increased substantially, by CNY 1160 (95\% Conference Interval [CI] 1155-1166), or about 28.7\% of its baseline level. Relative to the control group, patient out-of-pocket spending also increased, by CNY385 (95\% CI 382-399), or 16.9\% from baseline out-of-pocket spending in the intervention group. The overall inpatient reimbursement rate increased by about $5.66 \%$ (95\% CI 5.65\%-5.68\%) from the hospital reform in the intervention county, relative to the control county, after adjustment for patient characteristics. The average length of stay increased by half a day per inpatient stay, 0.51 (95\% CI 0.50-0.52), relative to the control group. This suggests that the increase 
in inpatient spending is mainly driven by the increase in charges per service day instead of the number of days per stay.

[Table II is about here]

Table III shows the policy effect on inpatient spending categorized by type of services. Relative to the control county, inpatient drug spending decreased by CNY147 (95\% CI 145-150), diagnostic testing increased by CNY248 (95\% CI 247-

249), physician services increased by CNY137 (95\% CI 136-139), and therapeutic services spending increased by CNY550 (95\% CI 548-551) in the intervention county.

[Table III is about here]

\section{Discussion}

Using a quasi-natural experiment design, we evaluated the effects of a major county public hospital reform in Hubei province in China. We found that total inpatient spending post policy increased by CNY1160, or $28.7 \%$ from baseline, and patient out-of-pocket spending increased by CNY385, or $16.9 \%$ from baseline out-ofpocket spending. Length of stay increased by 0.51 days, about $4.6 \%$ of baseline length of stay.

In our data, for the inpatient services that are covered by NCMS, the reimbursement rates were $49.2 \%$ in Danjiankou (intervention county) and $40.9 \%$ in Laohekou (comparison county) in 2011; and rates increased to $59.8 \%$ in Danjiankou and $45 \%$ in Laohekou in 2013. On the basis of all inpatient expenditures including services that were provided in the hospitals but were not covered by NCMS, the actual overall reimbursement rates were lower. For instance, in our data, the actual inpatient reimbursement rates were $43.6 \%$ in Danjiankou and 37.8\% in Laohekou in 2011, and the rates increased to $49.1 \%$ and $39.9 \%$ in 2013 , respectively. Our 
difference-in-differences approach estimated that the actual overall reimbursement rate in the reform county increased by 5.7 percentage points, relative to the control county. World Health Organization reported that between 2008 and 2010 the reimbursement rate increased about 5\% in cities selected for the pilot public hospital reform, but the reimbursement rate in cities is much higher than in rural China, at $64.5 \%$ in 2010 (World Health Organization).

One of the goals of the public hospital reform is to make inpatient services affordable to patients. Our study shows that although patients spent less on inpatient medications due to the zero mark-up drug policy, total patient out-of-pocket spending increased after the policy change. Although the actual reimbursement rate increased by 5.7 percentage points, net patient out-of-pocket spending increased $\$ 385$, and length of stay increased 0.51 days. When breaking-down by type of services, we found the largest increase in spending was from therapeutic services including intravenous infusion, electrotherapy, acupuncture, and nursing related services. This implies that part of the increase in total inpatient spending could be driven by supplyinduced demand (Chen et al., 2010, Ramesh and Wu, 2009). Drug sales were the largest income source before the reform (Yu et al., 2010, Zhao et al., 2013), accounting for about $45.5 \%$ of the total medical income of public hospitals in 2011 (National Health and Family Planning Commission of the People's Republic of China, 2012). To make up the reduced profits due to the zero markup on medications, the hospitals may provide more other services per day, or increase length of stay.

Our study has several limitations. First, we only have one intervention county and one control county from one province, and therefore our results may not be generalizable to other rural areas in China. However, the set of policy changes studied 
here represent general trend in public hospital reforms in the pilot counties in China. Second, our intervention and comparison groups may not have the exact same baseline trends in all spending variables. We used propensity score weighting method to balance the two groups, but it is possible they may differ in some unobserved characteristics. Third, we do not evaluate the change in the quality of care because of the lack of data, so we do not know whether part of the increase in inpatient spending is due to the improved quality of care.

To the best of our knowledge, our study is the first to evaluate the effect of the recent public hospital reform in rural China on inpatient spending using real-world insurance claims data. Although the reform required the public hospitals to reduce charges on diagnostic tests that use advanced technologies and therapeutic services, we found that total spending for these services increased substantially. In sum, we did not find the public hospital reform reduced total inpatient spending and patient out-ofpocket spending, but it does increase the actual reimbursement rate by 5.7 percentage points.

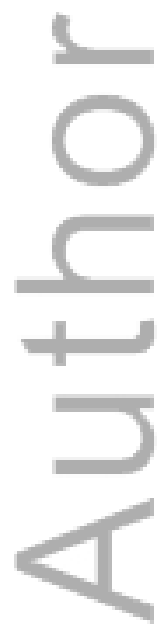




\section{References}

BARBER, S. L., BOROWITZ, M., BEKEDAM, H. \& MA, J. 2014. The hospital of the future in China: China's reform of public hospitals and trends from industrialized countries. Health Policy Plan, 29, 367-78.

CHEN, W., TANG, S., SUN, J., ROSS-DEGNAN, D. \& WAGNER, A. K. 2010. Availability and use of essential medicines in China: manufacturing, supply, and prescribing in Shandong and Gansu provinces. BMC health services research, $10,211$.

JING, S., YIN, A., SHI, L. \& LIU, J. 2013. Whether New Cooperative Medical Schemes reduce the economic burden of chronic disease in rural China. PloS one, 8, e53062.

LESLIE, R. S. \& GHOMRAWI, H. 2008. The use of propensity scores and instrumental variable methods to adjust for treatment selection bias [Online]. Available: $\quad$ http://www2.sas.com/proceedings/forum2008/366-2008.pdf [Accessed August 1 2015].

LI, Y., YING, C., SUFANG, G., BRANT, P., BIN, L. \& HIPGRAVE, D. 2013. Evaluation, in three provinces, of the introduction and impact of China's National Essential Medicines Scheme. Bull World Health Organ, 91, 184-94.

NATIONAL HEALTH AND FAMILY PLANNING COMMISSION OF THE PEOPLE'S REPUBLIC OF CHINA 2012. China health statistical yearbook (2012).

NEW COOPERATIVE MEDICAL SCHEME COUNCIL OF HUBEI PROVINCE 2012. The guidance of reimbursement plan of NCMS in Hubei Province in 2012. 
RAMESH, M. \& WU, X. 2009. Health policy reform in China: lessons from Asia. Soc Sci Med, 68, 2256-62.

THE GOVERNMENT OF HUBEI PROVINCE 2012. About the comprehensive pilot reform of county hospitals in Hubei Province(NO.56,2012).

THE STATE COUNCIL OF THE PEOPLE'S REPUBLIC OF CHINA 2012. The comprehensive pilot reform of county public hospitals.

WAGSTAFF, A., LINDELOW, M., JUN, G., LING, X. \& JUNCHENG, Q. 2009. Extending health insurance to the rural population: An impact evaluation of China's new cooperative medical scheme. Journal of health economics, 28, 1-19. WORLD HEALTH ORGANIZATION. Health Sector reform in China [Online]. Available:

http://www.wpro.who.int/china/mediacentre/factsheets/health_sector_reform/en 1.

YIP, W. C., HSIAO, W. C., CHEN, W., HU, S., MA, J. \& MAYNARD, A. 2012. Early appraisal of China's huge and complex health-care reforms. Lancet, 379, $833-42$.

YU, X., LI, C., SHI, Y. \& YU, M. 2010. Pharmaceutical supply chain in China: current issues and implications for health system reform. Health Policy, 97, 815.

ZHANG, Y., DONOHUE, J. M., LAVE, J. R., O'DONNELL, G. \& NEWHOUSE, J. P. 2009. The effect of Medicare Part D on drug and medical spending. New England Journal of Medicine, 361, 52-61.

ZHAO, L. P., YU, G. P., LIU, H., MA, X. M., WANG, J., KONG, G. L., LI, Y., MA, W., CUI, Y., XU, B., YU, N., BAO, X. Y., GUO, Y., WANG, F., ZHANG, J., 16 
LI, Y., XIE, X. Q., JIANG, B. G. \& KE, Y. 2013. Control costs, enhance quality, and increase revenue in three top general public hospitals in Beijing, China. PLoS One, 8, e72166.

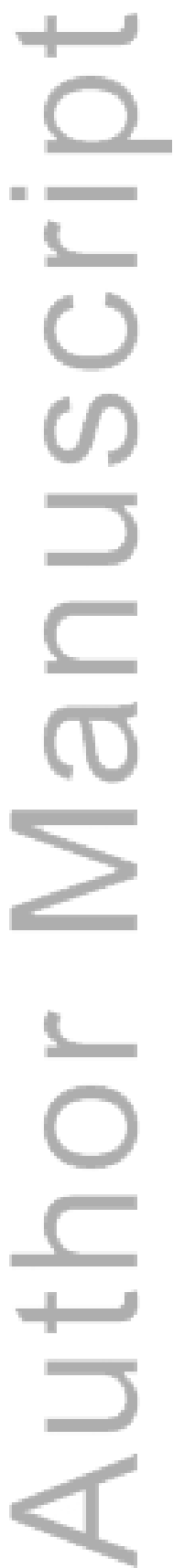


Figure Legends

Figure 1. Monthly Time Trend of Raw Inpatient Spending, Broken-Down By Out-of-Pocket Payment and Government Reimbursement Payment

Note:

Dangjiangkou is the intervention county and Laohekou is the control county.

Figure 2. Monthly Time Trend of Raw Inpatient Spending, by Type of Services Note:

Dangjiangkou is the intervention county and Laohekou is the control county.

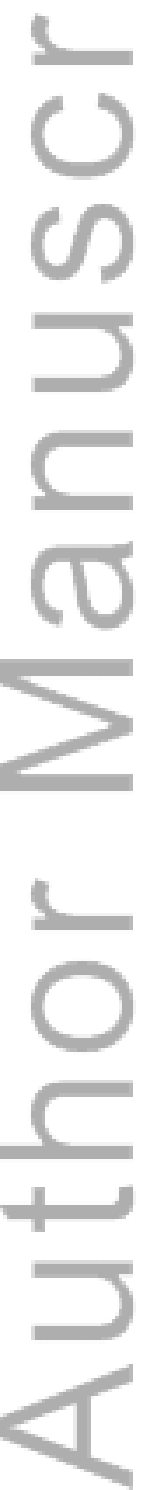


Table I. Summary Characteristics of Patients With Any Inpatient Stay in 2011

A. Raw data before propensity score weighting

\begin{tabular}{|c|c|c|c|}
\hline & $\begin{array}{c}\text { Danjiangkou } \\
\text { (Intervention) } \\
\mathrm{n}=6722 \\
\text { Mean } \\
\end{array}$ & $\begin{array}{c}\text { Laohekou } \\
\text { (Control) } \\
\mathrm{n}=9999 \\
\text { Mean } \\
\end{array}$ & P-Value \\
\hline Male, $\%$ & 45.8 & 48.4 & 0.001 \\
\hline Age, years old, $\%$ & 13.0 & 20.3 & \multirow[b]{2}{*}{0.000} \\
\hline- & $\begin{array}{l}17.0 \\
49.0 \\
21.3\end{array}$ & $\begin{array}{l}15.7 \\
44.8 \\
19.2\end{array}$ & \\
\hline $\begin{array}{l}\text { Head of household, } \% \\
\text { From the poor family, } \%\end{array}$ & $\begin{array}{l}39.6 \\
17.6\end{array}$ & $\begin{array}{l}35.9 \\
19.3\end{array}$ & $\begin{array}{l}0.000 \\
0.007\end{array}$ \\
\hline $\begin{array}{l}\text { Length of hospital stay, No. of } \\
\text { days }\end{array}$ & 11.0 & 11.0 & 0.675 \\
\hline \multicolumn{4}{|l|}{ Spending outcomes: } \\
\hline $\begin{array}{l}\text { Total inpatient spending, }{ }^{\text {a }} ¥, \\
\text { mean }\end{array}$ & 4039 & 4418 & 0.000 \\
\hline Inpatient drug spending, $¥$ & 1482 & 1314 & 0.000 \\
\hline Diagnostic testing spending, $¥$ & 809 & 1110 & 0.000 \\
\hline Physician services spending, $¥$ & 715 & 545 & 0.000 \\
\hline Therapeutic services spending, $¥$ & 724 & 996 & 0.000 \\
\hline Other inpatient spending, ¥ & 340 & 471 & 0.000 \\
\hline Government spending, ¥ & 1763 & 1669 & 0.011 \\
\hline Patient out of pocket spending, $¥$ & 2277 & 2749 & 0.000 \\
\hline Actual reimbursement rate, ${ }^{\mathrm{b}} \%$ & 43.6 & 37.8 & 0.000 \\
\hline
\end{tabular}


B. Weighted data after propensity score weighting

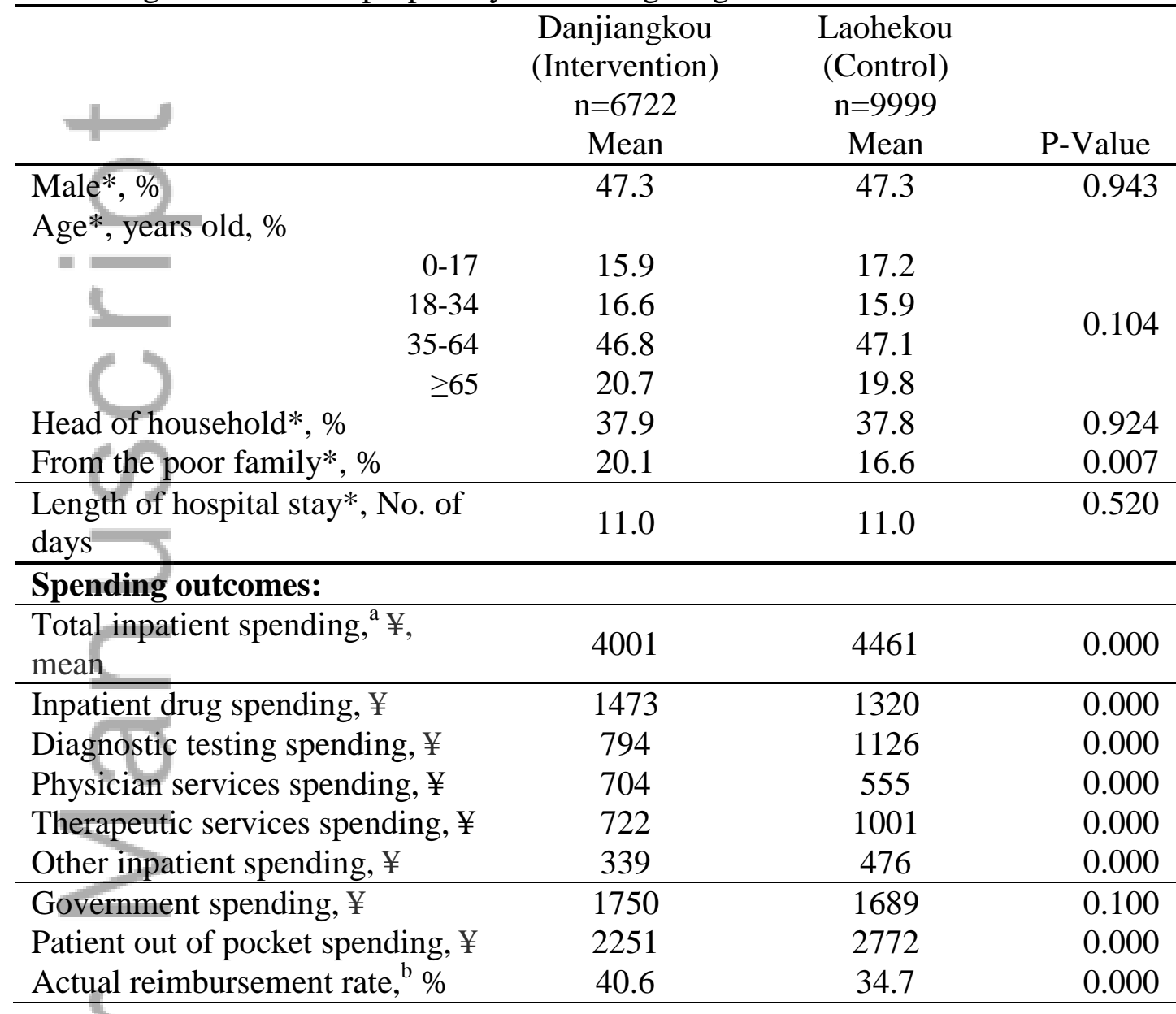

\section{Notes :}

*These variables are included in the calculation of propensity score weights.

${ }^{a}$ Total inpatient spending is the mean inpatient spending per inpatient stay;

${ }^{\mathrm{b}}$ Actual reimbursement rate is calculated as government spending divided by total inpatient spending for all inpatient expenditures, including expenditures that are not reimbursable by the New Cooperative Medical Scheme in rural China. Thus, this number is lower than the reimbursement rate for the reimbursable expenditures. 
Table II. Policy Effects on Inpatient Spending, Out-of-Pocket Spending, Reimbursement Rate and Length of Stay

Part A. Regression Results from the Difference-in-Differences Approach

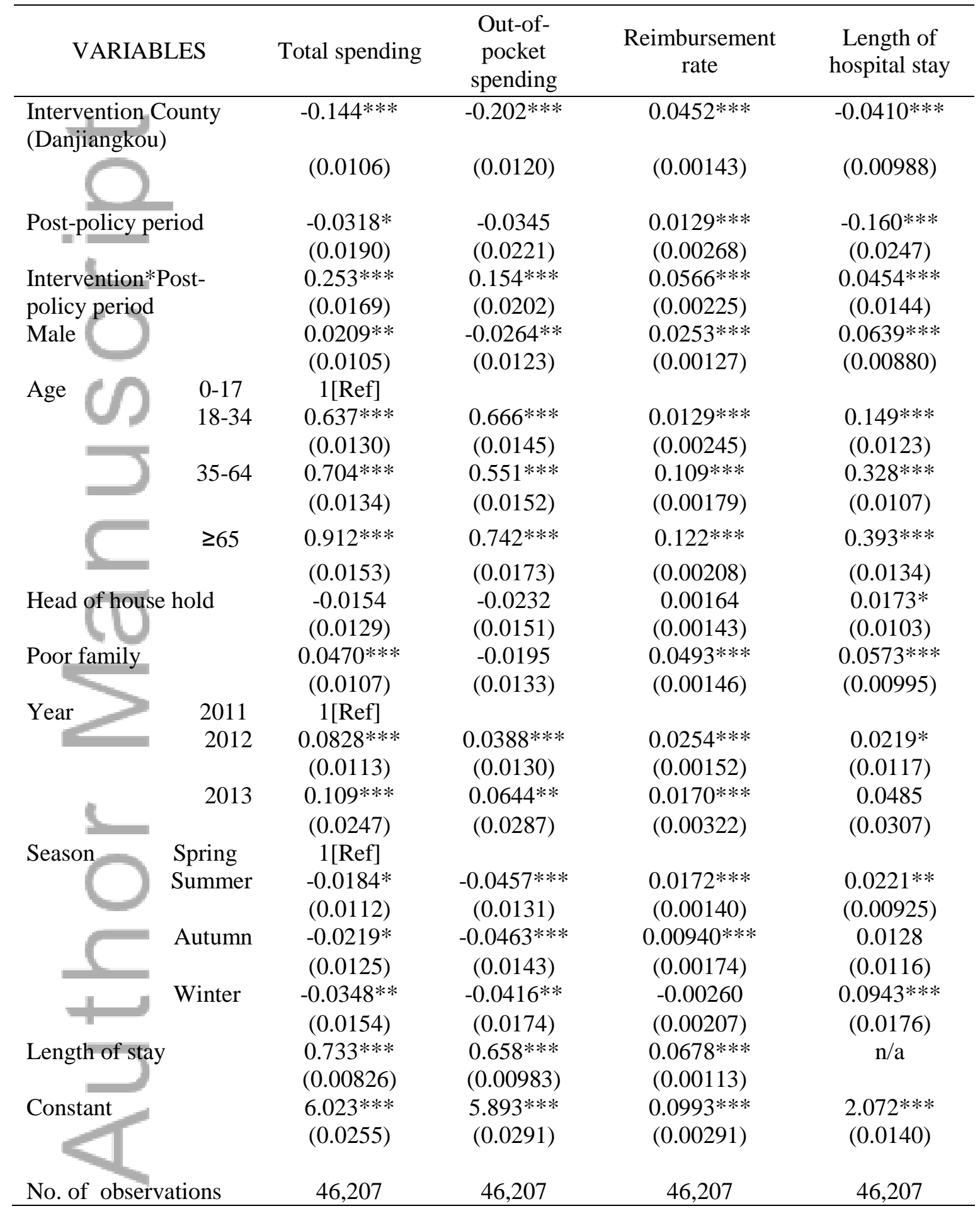

Notes: Standard errors are in parentheses. $* * *$ denotes $\mathrm{p}<0.01$, ** denotes $\mathrm{p}<0.05$, and $*$ denotes $\mathrm{p}<0.1$.

1 [Ref] denotes the reference group. 
Part B. Predicted Policy Effects Based on the Above Regression Results and Bootstrapping

\begin{tabular}{lcccc}
\hline & $\begin{array}{c}\text { Total } \\
\text { spending, } ¥\end{array}$ & $\begin{array}{c}\text { Out-of- } \\
\text { pocket } \\
\text { spending, } ¥\end{array}$ & $\begin{array}{c}\text { Reimbursemen } \\
\text { t rate, } \%\end{array}$ & $\begin{array}{c}\text { Length of } \\
\text { hospital stay, } \\
\text { No. of days }\end{array}$ \\
\hline Policy Effect & 1,160 & 385 & 5.66 & 0.51 \\
\hline S.E. & 2.62 & 1.72 & 0.0001 & 0.0049 \\
\hline $95 \%$ CI & $(1155,1166)$ & $(382,389)$ & $(5.65,5.68)$ & $(0.498,0.517)$ \\
\hline
\end{tabular}

Notes: Our key identification strategy is difference-in-differences approach to estimate the pre- and post- changes in all outcomes in the intervention county, relative to the changes in the control county. To further balance the intervention and control groups, we used a propensity score weighting mechanism. We estimated predicted values for pre- and post- policy outcomes separately for the intervention and control groups and used bootstrapping techniques with 1000 replications to estimate the standard errors for difference-in-differences estimates.

$\mathrm{CI}=$ Confidence Interval; S.E. $=$ these are standard errors from 1000 replications of bootstrapping.

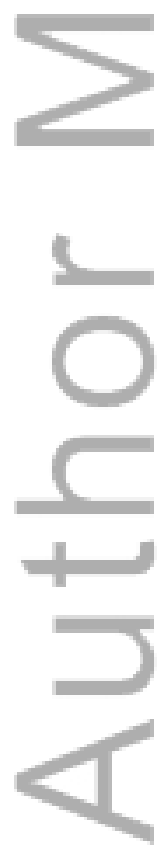


Table III. Policy Effects on Inpatient Spending by Type of Services

Part A. Regression Results from the Difference-in-Differences Approach

\begin{tabular}{|c|c|c|c|c|c|}
\hline VARIABLES & $\begin{array}{c}\text { Inpatient } \\
\text { Medications }\end{array}$ & $\begin{array}{l}\text { Diagnostic } \\
\text { Tests }\end{array}$ & $\begin{array}{l}\text { Physician } \\
\text { Services }\end{array}$ & $\begin{array}{c}\text { Therapeutic } \\
\text { Services }\end{array}$ & Others \\
\hline \multicolumn{6}{|l|}{ Intervention } \\
\hline \multicolumn{6}{|l|}{ County } \\
\hline (Danjiangkou) & $0.0263 * *$ & $-0.384 * * *$ & $0.118 * * *$ & $-0.298 * * *$ & $-0.181 * * *$ \\
\hline 1 & $(0.0108)$ & $(0.0117)$ & $(0.0205)$ & $(0.0164)$ & $(0.0334)$ \\
\hline \multirow[t]{2}{*}{ Post-policy period } & $0.128 * * *$ & $-0.167 * * *$ & $0.0981 * * *$ & $-0.270 * * *$ & -0.0804 \\
\hline & $(0.0223)$ & $(0.0214)$ & $(0.0349)$ & $(0.0384)$ & $(0.0495)$ \\
\hline \multicolumn{6}{|l|}{ Intervention*Post- } \\
\hline \multirow{2}{*}{$=$ policy period } & $-0.0952 * * *$ & $0.219 * * *$ & $0.138 * * *$ & $0.691 * * *$ & $0.591 * * *$ \\
\hline & $(0.0272)$ & $(0.0196)$ & $(0.0290)$ & $(0.0291)$ & $(0.0519)$ \\
\hline \multirow{2}{*}{ Male } & $0.0699 * * *$ & 0.0147 & -0.0201 & $0.0473 * * *$ & -0.0288 \\
\hline & $(0.0201)$ & $(0.0110)$ & $(0.0173)$ & $(0.0165)$ & $(0.0445)$ \\
\hline $0-17$ & $1[$ Ref $]$ & & & & \\
\hline \multirow{2}{*}{$18-34$} & $0.311 * * *$ & $0.712 * * *$ & $1.193 * * *$ & $0.585^{* * *}$ & $0.587 * * *$ \\
\hline & $(0.0171)$ & $(0.0191)$ & $(0.0254)$ & $(0.0175)$ & $(0.0324)$ \\
\hline \multirow[t]{2}{*}{$35-64$} & $0.528 * * *$ & $0.993 * * *$ & $0.774 * * *$ & $0.674 * * *$ & $0.592 * * *$ \\
\hline & $(0.0221)$ & $(0.0180)$ & $(0.0261)$ & (0.0199) & $(0.0365)$ \\
\hline \multirow[t]{2}{*}{$\geq 65$} & $0.743 * * *$ & $1.209 * * *$ & $0.782 * * *$ & $1.131 * * *$ & $0.754 * * *$ \\
\hline & $(0.0372)$ & $(0.0198)$ & $(0.0297)$ & $(0.0235)$ & $(0.0394)$ \\
\hline \multicolumn{6}{|l|}{ Head of } \\
\hline \multirow[t]{4}{*}{ house hold } & -0.0154 & 0.0114 & $0.0986 * * *$ & $-0.0558 * * *$ & 0.0554 \\
\hline & $(0.0231)$ & $(0.0123)$ & $(0.0201)$ & $(0.0204)$ & $(0.0543)$ \\
\hline & $0.0471 * * *$ & $0.0417 * * *$ & $0.0602 * * *$ & $0.125 * * *$ & 0.0183 \\
\hline & $(0.0133)$ & $(0.0119)$ & $(0.0189)$ & $(0.0171)$ & $(0.0362)$ \\
\hline \multicolumn{6}{|l|}{2011} \\
\hline \multirow[t]{2}{*}{2012} & $0.0516^{* * *}$ & $0.159 * * *$ & $0.268 * * *$ & $-0.100 * * *$ & $0.0773 * *$ \\
\hline & $(0.0117)$ & $(0.0118)$ & $(0.0218)$ & $(0.0178)$ & $(0.0375)$ \\
\hline \multirow[t]{2}{*}{2013} & $0.0736^{* *}$ & $0.310 * * *$ & $0.420 * * *$ & $-0.224 * * *$ & 0.0803 \\
\hline & $(0.0296)$ & $(0.0269)$ & $(0.0443)$ & $(0.0418)$ & $(0.0824)$ \\
\hline \multirow{3}{*}{$\begin{array}{r}\text { Season } \\
\text { Spring } \\
\text { Summer }\end{array}$} & 1 [Ref] & & & & \\
\hline & $-0.0321 *$ & 0.00341 & $0.0756^{* * * *}$ & 0.0156 & -0.00875 \\
\hline & $(0.0168)$ & $(0.0117)$ & $(0.0190)$ & $(0.0180)$ & $(0.0416)$ \\
\hline \multirow{2}{*}{ Autumn } & $-0.0572 * * *$ & $0.0311 * *$ & 0.0105 & $-0.0566 * * *$ & 0.00686 \\
\hline & $(0.0144)$ & $(0.0140)$ & $(0.0239)$ & (0.0208) & $(0.0363)$ \\
\hline \multirow{6}{*}{ Winter } & $-0.0548 * * *$ & $0.0670 * * *$ & $0.0830 * * *$ & $-0.155^{* * *}$ & $-0.0873 * *$ \\
\hline & $(0.0174)$ & $(0.0175)$ & $(0.0284)$ & $(0.0253)$ & $(0.0440)$ \\
\hline & $0.930 * * *$ & $0.543 * * *$ & $0.905^{* * *}$ & $0.628 * * *$ & $0.812 * * *$ \\
\hline & $(0.0206)$ & $(0.00826)$ & $(0.0147)$ & $(0.0112)$ & $(0.0330)$ \\
\hline & $4.525 * * *$ & $4.832 * * *$ & $3.507 * * *$ & $4.708 * * *$ & $3.645^{* * *}$ \\
\hline & $(0.0328)$ & $(0.0247)$ & $(0.0454)$ & $(0.0326)$ & $(0.109)$ \\
\hline $\begin{array}{r}\text { No. of } \\
\text { observations } \\
\end{array}$ & 46,207 & 46,207 & 46,207 & 46,207 & 46,207 \\
\hline
\end{tabular}

Notes: Robust standard errors are in parentheses. $* * *$ denotes $\mathrm{p}<0.01, * *$ denotes $\mathrm{p}<0.05$, and $*$ denotes $\mathrm{p}<0.1 .1[\mathrm{Ref}]$ denotes the reference group. 
Part B. Predicted Policy Effects Based on the Above Regression Results and Bootstrapping

\begin{tabular}{lccccc}
\hline & $\begin{array}{c}\text { Inpatient } \\
\text { Medications }\end{array}$ & $\begin{array}{c}\text { Diagnostic } \\
\text { Tests }\end{array}$ & $\begin{array}{c}\text { Physician } \\
\text { Services }\end{array}$ & $\begin{array}{c}\text { Therapeutic } \\
\text { Services }\end{array}$ & Others \\
\hline Policy Effects & -147 & 248 & 137 & 550 & 299 \\
S.E. & 1.36 & 0.66 & 0.77 & 0.77 & 0.91 \\
\hline $95 \%$ CI & $(-150,-145)$ & $(247,249)$ & $(136,139)$ & $(548,551)$ & $(297,301)$ \\
\hline
\end{tabular}

Notes: Our key identification strategy is difference-in-differences approach to estimate the pre- and post- changes in all outcomes in the intervention county, relative to the changes in the control county. To further balance the intervention and control groups, we used a propensity score weighting mechanism. We estimated predicted values for pre- and post- policy outcomes separately for the intervention and control groups and used bootstrapping techniques with 1000 replications to estimate the standard errors for difference-in-differences estimates.

$\mathrm{CI}=$ Confidence Interval; S.E. $=$ these are standard errors from 1000 replications of bootstrapping.

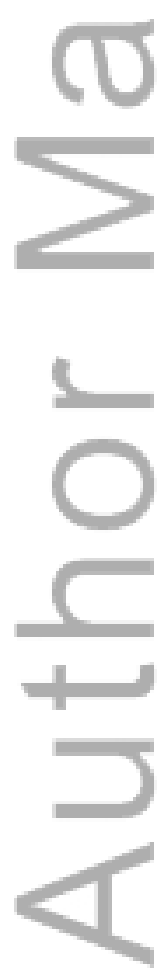




\section{University Library}

\section{- M M I N E R VA A gateway to Melbourne's research publications}

Minerva Access is the Institutional Repository of The University of Melbourne

Author/s:

Zhang, Y;Ma, Q;Chen, Y;Gao, H

Title:

Effects of Public Hospital Reform on Inpatient Expenditures in Rural China

Date:

2017-04-01

Citation:

Zhang, Y., Ma, Q., Chen, Y. \& Gao, H. (2017). Effects of Public Hospital Reform on

Inpatient Expenditures in Rural China. HEALTH ECONOMICS, 26 (4), pp.421-430. https:// doi.org/10.1002/hec.3320.

Persistent Link:

http://hdl.handle.net/11343/290904 